\title{
The Use of M-Learning: A Perspective of Learners' Perceptions on M-Blackboard Learn
}

\author{
https://doi.org/10.3991/ijim.v15i02.17003 \\ Abdulmohsin Suliman Alkhunaizan \\ Majmaah University, Majmaah, Saudi Arabia \\ Raja Muhammad Ishtiaq Khan ${ }^{(凶)}$ \\ Majma'ah University, Zulfi, Kingdom of Saudi Arabia \\ r. khan@mu.edu.sa
}

\begin{abstract}
The life of the common to the students have changed due to spread of COVID-19 9 all around the globe. All the educational institutions were also set to be functioned remotely following the global instructions to meet the challenges to combat the COVID-19. The of current inquiry is the explore the male and female learners on the use of mobile phones for Blackboard learn. The Study survey method to collect the data. 68 participants of the medical majors of the CFY formed the sample for the present study. The findings of the study indicate that learners preferred to use M-blackboard. The results also indicated that backboard which is a form of e-learning can be beneficial if it is used with the traditional classroom teaching to get the potential benefits of the software.
\end{abstract}

Keywords-Blackboard, M-learning, Perceptions, E-learning

\section{Introduction}

The life of the common to the students have changed due to spread of COVID 19 all around the globe. All most of the institutions were closed at the onset of 2020. All the educational institutions were also set to be functioned remotely following the global instructions to meet the challenges to combat the COVID-19. To this end the institutions used different online modes to teach the students across the kingdom. Educational institutions in the kingdom are already implementing E-learning in most of the higher-educational institutions (Alhabeeb \& Rowley, 2017; Muhammad et al., 2020; Quadri et al., 2017). The extensive availability of the modern technological gadgets and the internet has fortified most of the institutions related to education across the globe. The led to many advantages in the form of blended learning to enhance the learning pursuits (Al-Emran \& Salloum, 2017; Dziuban et al., 2018; Khan et al., 2019; Shahbaz \& Khan, 2017).

Hsu (2016) asserts that the technological integration can be implemented by taking consideration of humanness, time, dependability, and availability of the technology. 
In fact, the present transformations have set in the teaching sector by the technological integration in education. The present use of the technology greatly relies on the inventions of the modern technological in gadgets including, computers, laptops, smartphones and various other handheld smart devices. The flexibility of the technological device made it easy to integrate it in the institutions in many different forms (Bulman \& Fairlie, 2016; Ramírez-Montoya \& Hernández, 2016). Recently the technology has been remained persistent in the many institutions of the Saudi Arabia. Teachers are integrating many computer and smartphone devices to teach numerous subjects (Khan et al., 2018).

Plethora of hi-tech devices and applications are being used to develop and foster the educational methods in educational institutions. These types of hi-tech facilities have the abilities of transformation from conventional to digital ways of instruction in education sector. This led education system to innovation and creativity which is effective for developing and attaining the quality of education (Glukhov \& Vasetskaya, 2017). Learning Management Systems (LMS) have been integrated in numerous institutions as a learning tool in various disciplines. The accessibility, ubiquity, and ease of its integration with conventional classroom teaching made it applicable in educational institutions. One of the main established form of the LMS is blackboard software which is implemented in many universities. Heirdsfield et al. (2011) argued that blackboard is referred to as a software package developed to assist educationalists in creating quality oriented online courses. Most of the higher education institutions are implementing this software and it is becoming popular around the globe. Ibrahim et al. (2019) found that this software has numerous features which can foster teaching and learning. It is the easiest mode of promoting the interaction among teachers and students. Owing to its attractive features, mobile learning can be used by educators for a more effective and enjoyable learning experience

The use of mobile phone gadgets and its applications appeal the learners concentration in different field of the education (Dorouka et al., 2020). Moreover, the use of smartphones proposes a more beneficial and pleasing learning environment due to its eye-catching features (Kalogiannakis \& Papadakis, 2017; Papadakis et al., 2016). This has increased a huge volume of literature in academia, and various initiatives for the implementation of E-learning in the education institutions. The use of the mobile phones' application needs a careful consideration for using it for a particular aspect of the learners' need. This all depends how instructors, parents, and guide choose the application (Papadakis et al., 2020). Students learning proficiency fosters by the use of distant Moodle activities by the use of mobile phones (Papadakis et al., 2018). However, Papadakis et al. (2018) assert that due to compatibility and usability of the mobile phones learners do not feel comfortable in using LMS on Mobile phones.

One of the key benefits of this system is it offers diverse ways to involve learners outside of the conventional classroom. The use of distant tools in this software devised for the learners to approach the learning material and a platform of interaction (Jacob \& Issac, 2008; Kitoo, 2020). For the instructors, it contains useful tools to devise course contents flexibility. It also offers instructors to create forums for discussion and interactive assignments. It has an interesting preface which allows students to submit their homework and assignment and they can track their performance on 
their own. Moreover, the use it has a good mechanism of keeping the record of all the quizzes, tests and emails of the teachers and students. This software also provides instructors with the ability to make and monitor the groups. Learners can take part in the live discussion with the group members. Blackboard has an interesting mechanism of follow up which is regarded as very significant in the learning system. One of the key features that distinguishes it with other software is that it has a diverse system of creating and administrating the exams effectively. Figure 1 illustrates the three modes of the e-learning.

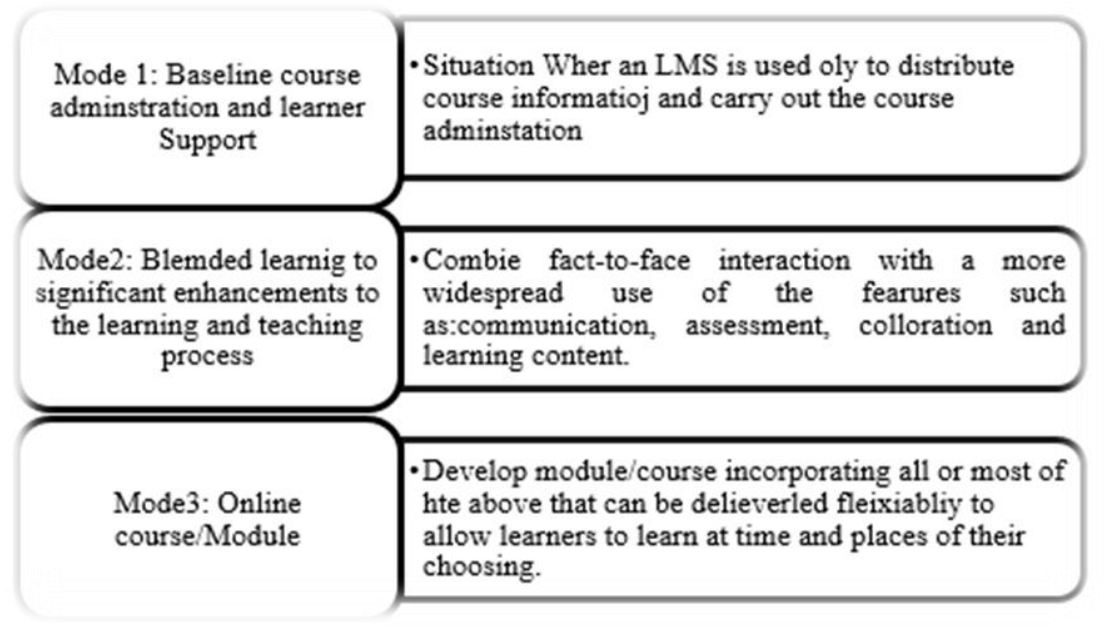

Fig. 1. Levels of E-learning adopted from (Papadakis et al., 2017)

\section{E-Learning and Blackboard in KSA}

The use of e-learning was initiated by the King Fahad university in the year 1993 (Al-Asmari \& Khan, 2014). The was the first attempt to connect an institution with the internet. To develop e-learning in the kingdom the government has founded a national center for "e-learning and distance learning". The main purpose of the establishment of the national center was "an additional value to aid and foster the conventional teaching mechanism and sprouting a dynamic integrated educational environment for the teachers and learners. The aim of the center was to launch pertinent programs, projects, and preparation of the material of e-learning and its implementation. Saudi Digital Library (SDL) is one of the earliest established projects of this center to cater and meet the required challenges in the applicability of the e-learning effectively. Today, most of the institutions are benefiting from the SDL in the shape for free online resources including books, e-journal, workshops, and other research related software to meet the international standard of the research. This database includes most of the international publishers' data for the students, teachers, and researchers available freely. 
Another vital initiative was taken by the government in 2008 in order to develop an a plan to implement information technology throughout the country for the implementation of e-learning in the education (Alkhunzain, 2019; Quadri et al., 2017). As a result, all the universities have initiated the e-learning program under the deanships of the information technology and endorsed the collaboration covenants with the prominent international organizations to provide training and logistic services for the elearning platform in the country. Moreover, Saudi Electronic University was also evolved in 2011 to start the distance learning in the kingdom and it is the only institution which offers various programs for undergraduate and graduate students. At present most of higher education institutions with the help of national center are incorporating e-learning modes in the shape of blended learning, web based learning or fully online. Heirdsfield et al. (2011) argued that the implementation of e-learning is reached due to the mutual interaction, technological incorporation, and viability of various learning styles.

The availability of the e-learning platform was a great benefit to all the institutions to implement the online and remote teaching in the kingdom when the pandemic COVID-19 appeared in the world and affected the education system. The researcher feels proud to disclose that Majmaah university teaching program was not stopped even a single day during this situation. The reason of this was the institution has already had the blended learning program using Balckboard. One of the foremost online LMS form is Blackboard, which has been utilized for the application of e-learning in many countries. It is regarded as a handy mode of interaction, sharing information and communication. It facilitates a good paired coaching and support to both teachers and students to develop the individual and group learning. One of the main advantages of the Blackboard is that it offers up-to-date technology to the users (Little-Wiles \& Naimi, 2011). Blackboard has confirmed to an efficacious LMS. In spite of sporadic assertions about it usage difficulties in the implementation because of the knowledge of the technology (Al Meajel \& Sharadgah, 2018) it is easy to use and has many advantages (Kashghari \& Asseel, 2014).

Blackboard is effective in term of the delivering material to the learners. Learners also regard this e-learning platform as an operative software in learning. It is obvious that teachers primarily integrate Blackboard as an instrument for improvement motives, rather than transformation in advancing teaching methods (Heirdsfield et al., 2011). With the development of the technology, it can also be used in the smartphones easily (Brand et al., 2011). Learners do not need to sit in the lab or at a place where they can use their laptop or computer.

El Miedany (2019) assert that mobile phones and modern PDAs are the frequently integrated devices for the implementation of m-learning, and they have the capability to replace the newly developed emerging technologies. Now modern mobile phones are being integrated in education institutions for sharing the material and even online teaching. In Saudi Arabia teachers are utilizing mobile phones in teaching various subjects. Even though m-learning is persistent in the Saudi institution, but there is a scarcity of the studies that determine the learners' perceptions on the usage of mobile phone devices for promoting e-learning. In this regard the use of blackboard through 
mobile phone is less researched area. Therefore, the aim of current inquiry is to investigate learners' opinion on the usage of Blackboard through smart phones.

Blackboard mobile learn is a mobile based application that can be freely downloaded from the play or apple store. It needs institutions ID and password to use it. The institutions usually link all the students registered in a course with the Blackboard, which can be used on mobile phones and other electronic devices including computers and laptops. After the activation both learners and teachers can access to their courses, and online class interactive class, create and upload homework, assignments, quizzes and even exam can also be effectively conducted through the backboard. The use of the online interactive class was one the key advantages to most of the universities in the Kingdom during the pandemic outbreak. All the institutions of higher education launched online learning during this period. Mobile phones as a tool in m-learning, Blackboard application has predicted the possible revolution in the education.

Mobile Blackboard has certain features that have an important impact on the learner's usage perception of Blackboard through the mobile phones. This should be taken into the consideration for the effective implementation of online learning to attain the potential benefits of the education and learning. Previous research did not emphasis on the institution use of the technology in order to implement the learning. Alkhaldi and Abualkishik (2019) investigated the possible advantages and challenges of MLMS in higher education recently. The findings exhibited that students are confronting problems in attaining the desired advantages of the M-LMS. Though there appeared some frequency differences on certain elements of the learners' responses. Another study by Han and Shin (2016) studied the factors that affect the Blackboard learning. The results highlighted that the learners' self-efficacy in using M-blackboard has the perceived benefits in using the LMS. Moreover, the results indicated that learners had the encouraging remarks on the integration of Blackboard.

The result of this study was endorsed by the studies by (Alshammari et al., 2016; Alshammari et al., 2018), who evaluated the acceptance of the LMS and self-efficacy. In addition to this they had asserted that technological and institutional aspects are also some of the challenges that learners and teachers face during the implementation of the Blackboard learning. This assert that the use of Blackboard can be handy if it is used as blended learning environment. Another study conducted by Asiimwe (2015) on the ease of use of M-LMS. The results indicated that the learner didn't like the idea of using Blackboard through mobile phones. However, Kaliisa and Picard (2017) study results showed that learners considered using blackboard useful through their mobile phones. Likewise, Mtebe and Raisamo (2014) asserted that learners showed willingness to use M-LMS. In the light of reviewed literature is found that to-date, there no study exists in the Saudi-context which investigated the gender differences on the usage of M-LMS. Thus, the focus of current inquiry is the explore the male and female learners on the use of mobile phones for Blackboard learn. The study aims to answer the following research questions.

1. What are the learners' perceptions on the usage of M-blackboard learn?

2. Are there any differences of gender in the perception of M-blackboard learning? 
3. What is the learners' preference of the usage of application in regard to Zoom and Blackboard learn?

\section{Methodology}

The main focus of the present inquiry was to determine learners' perceptions on the use of M-blackboard learn. For research employed the survey method to examine the learners' perception on the M-Blackboard learn. The focused population of the current population are the Common First Year Students (CFY) of the Majmaah University. The participants of the study are the medical students of the CFY section, CFY is prerequisite for entering into various majors in all the universities in the Saudi Arabia. Convenience sampling technique was employed to choose the participants of the present inquiry. Convenience sampling allows researchers to fulfill the evident criteria that is availability, accessibility to participants at a particular time, or the readiness to take part in a study (Etikan et al., 2016). Zhang et al. (2017) affirm that the use of survey method is observed as a prevalent method in the research studies. To this researcher has administered a questionnaire to meet the aim of the present inquiry. The questionnaire helped researcher to gather the learners' perception data. 68 participants of the medical majors of the CFY formed the sample for the present study. The table below displays the demographic distribution of the inquiry.

Table 1. Demographic background

\begin{tabular}{|c|c|c|c|c|}
\hline Serial No & Gender & Frequency & Percentage & Major \\
\hline 1 & Male & 32 & $48 \%$ & Medical \\
\hline 2 & Female & 36 & $52 \%$ & Medical \\
\hline 3 & Total & 68 & 100 & Medical \\
\hline
\end{tabular}

Due to spread of COVID-19, all the universities have implemented remote teaching. The students of the CFY year were also taught online by using two soft wares suggested by the education ministry and IT Deanship. Therefore, it was also essential to measure the learners' preference of the usage of e-learning tool. SPSS 22 was used to analyze the data for the present inquiry.

\subsection{Instruments}

For the survey method a questionnaire was used for the data collection. Patten (2016) states that the use of the questionnaire is useful for conducting a research and can construct the frequencies of the responses, which are suitable for the analysis and flexible for statistical measure purposes. The questionnaire was adopted from previous study Asiimwe (2015) and modified to the context of Mblackboard learn. After the construction of the questionnaire, it was sent to experts in the arena of research methodology to validate the construct of the questionnaire items. The questionnaire consisted of the 15 items of which 12 items were about the perceptions of the usage of the Mblackboard, 2 items were for the perceived problems and 1 item was to underpin 
learners' preference of the application used for learning purposes that is Zoom and MLMS. Learners' were asked in response the Likert scale from strongly agree (5) to strongly disagree (1) to record their choice. The questionnaire was sent electronically to all the participants. The responses of the participants were coded, and reliability analysis was taken before the analysis of the data. The following table portrays the reliability analysis of the questionnaire.

Table 2. Reliability Analysis of the Questionnaire

\begin{tabular}{|l|c|c|l|}
\hline \multicolumn{5}{|c|}{ Reliability Statistics } \\
\hline \multicolumn{1}{|c|}{ Questionnaire part } & No of Items & Cronbach's AlPha & \multicolumn{1}{c|}{ Remarks } \\
\hline First Part & 12 & .923 & High Reliability \\
\hline Second Part & 2 & .945 & High Reliability \\
\hline Third Part & 1 & .912 & High Reliability \\
\hline
\end{tabular}

It is vital from the table that all the parts of the questionnaire have exceptional Cronbach's values $(.923, .945$ and .912). Therefore, the questionnaire is regarded as reliable.

\section{$4 \quad$ Data Analysis}

The analysis of the of learners' perception M-Blackboard learn was carried out. To attain the results, data were imported to SPSS to seek the statistical output of the data. For this descriptive statistical measure was employed. Table 3 explains the learners' perception on the usage of Blackboard application.

Table 3. Perception on M-LMS

\begin{tabular}{|c|c|c|c|c|c|c|c|}
\hline Items & SA & $\mathbf{A}$ & $\mathbf{N}$ & $\mathbf{D}$ & SD & $\mathbf{M}$ & SD \\
\hline Blackboard facilitates learning greatly & $32 \%$ & $22 \%$ & $15 \%$ & $15 \%$ & $16 \%$ & 3.2 & 1.6 \\
\hline Blackboard provides a great benefit in learning & $19 \%$ & 26 & $11 \%$ & $21 \%$ & $20 \%$ & 2.9 & 1.4 \\
\hline Blackboard helps in understanding the material content & $9 \%$ & $16 \%$ & $16 \%$ & $23 \%$ & $35 \%$ & 2.4 & 1.4 \\
\hline Blackboard will be a necessity for all students in the future & $15 \%$ & $36 \%$ & $12 \%$ & $19 \%$ & $17 \%$ & 3.1 & 1.4 \\
\hline Doing assignments and homework through Blackboard is better & $35 \%$ & $12 \%$ & $9 \%$ & $20 \%$ & $24 \%$ & 3.1 & 1.6 \\
\hline $\begin{array}{l}\text { Blackboard is a replacement of learning to learn without the need to } \\
\text { attend the university }\end{array}$ & $22 \%$ & $13 \%$ & $12 \%$ & $20 \%$ & $33 \%$ & 2.7 & 1.6 \\
\hline $\begin{array}{l}\text { The information through Blackboard is more than what I get in the } \\
\text { usual class }\end{array}$ & $6 \%$ & $5 \%$ & $15 \%$ & $13 \%$ & $62 \%$ & 1.8 & 1.2 \\
\hline Blackboard helped me to self-learning & $24 \%$ & $12 \%$ & $12 \%$ & $15 \%$ & $38 \%$ & 2.7 & 1.6 \\
\hline $\begin{array}{l}\text { Blackboard helps me to learn without commitment at any place or } \\
\text { time }\end{array}$ & $33 \%$ & $28 \%$ & $6 \%$ & $6 \%$ & $28 \%$ & 3.3 & 1.6 \\
\hline Blackboard increases the interaction between teacher and learner & $6 \%$ & $12 \%$ & $13 \%$ & $20 \%$ & $49 \%$ & 2.1 & 1.3 \\
\hline Blackboard provides quick delivery of information to students & $20 \%$ & $22 \%$ & $12 \%$ & $20 \%$ & $25 \%$ & 2.9 & 1.5 \\
\hline Internet speed creates problems & $34 \%$ & $15 \%$ & $10 \%$ & $9 \%$ & $33 \%$ & 2.1 & 1.5 \\
\hline I face audio and video problems & $31 \%$ & $15 \%$ & $6 \%$ & $15 \%$ & $33 \%$ & 1.9 & 1.1 \\
\hline
\end{tabular}

Learners' perceptions were computed through SPSS. Table 1 indicates that the use of Blackboard application was considered effective. A vital proportion $(n=32 \%)$ 
strongly agreed that Blackboard facilitates learning and $(\mathrm{n}=22 \%)$ agreed with this notion. Whereas only relatively small number of the learners $(\mathrm{n}=15 \%)$ consider this ineffective. The mean value ( $\mathrm{M}=3)$ and $\mathrm{SD}(1.6)$ indicated that learners' perception was near to agree. This shows that the use of the smartphones for using blackboard activities have the potential to develop the learners learning abilities. Moreover, the use of Smartphones facilitates the learning process. The response to self-learning was noted as $(\mathrm{n}=24 \%)$ strongly agreed, relatively less proportion $(\mathrm{n}=12 \%)$ agree with this aspect, in contrast $(\mathrm{n}=38 \%)$ disagreed in this regard, which is a relatively high proportion. The mean value $(\mathrm{M}=2.7)$ and $(\mathrm{SD} 1.6)$ were also appeared low. This demonstrates that self-learning, which is an essential facet of learning, can also be attained effectively. Likewise, the in the quick delivery of the information for the students also appeared to be on the average value of the statistics. The responses of the learners indicate that $(\mathrm{n}=20 \%)$ acknowledged this idea as strongly agreed, which is followed by $(\mathrm{n}=22 \%)$ agree. However, most of the learners did not endorse this idea $(\mathrm{n}=25 \%)$ strongly disagreed and $(\mathrm{n}=20 \%)$ disagreed.

With the challenge aspect of the usage of the Mblackboard learners' responses were also somehow not satisfactory. Most of the learners $(n=34 \%)$, which is relatively higher proportion", indicated that internet speed creates problems, this is tailed by $(\mathrm{n}=15 \%)$. This indicates that the learners' perceptions were influenced by certain factors that hinders the usage of the mobile phone devices. However, a similar type of the remarks was appeared as that internet is not a problem. In this regard $(\mathrm{n}=33 \%)$ disagreed with this assertion. Table 2 describes the gender differences on the perception of the Mblackboard learn.

Table 4. Gender Differences

\begin{tabular}{|c|c|c|c|c|c|c|c|c|}
\hline \multicolumn{2}{|c|}{ Crosstabulation*Gender Differences } & & SA & $\mathbf{A}$ & $\mathbf{N}$ & D & SD & Total \\
\hline \multirow{2}{*}{$\begin{array}{l}\text { BB Adop- } \\
\text { tion }\end{array}$} & \multirow{2}{*}{ Perceived ease of Use of M-LMS } & Male & 10 & 8 & 4 & 4 & 6 & 32 \\
\hline & & Female & 12 & 3 & 6 & 7 & 8 & 36 \\
\hline & \multirow{2}{*}{ Beneficial for learning } & Male & 6 & 12 & 4 & 4 & 6 & 32 \\
\hline & & Female & 5 & 6 & 4 & 11 & 10 & 36 \\
\hline & \multirow{2}{*}{ Material delivery } & Male & 4 & 8 & 6 & 6 & 8 & 32 \\
\hline & & Female & 2 & 3 & 5 & 10 & 16 & 36 \\
\hline & \multirow{2}{*}{ Developed Interaction } & Male & 12 & 12 & 2 & 0 & 6 & 32 \\
\hline & & Female & 10 & 7 & 2 & 4 & 13 & 36 \\
\hline & \multirow{2}{*}{ Assignment, Homework delivery } & Male & 12 & 4 & 6 & 4 & 6 & 32 \\
\hline & & Female & 12 & 4 & 0 & 10 & 10 & 36 \\
\hline & \multirow{2}{*}{ Replacement of Conventional Learning } & Male & 6 & 8 & 2 & 8 & 8 & 32 \\
\hline & & Female & 9 & 1 & 6 & 6 & 14 & 36 \\
\hline
\end{tabular}

To determine the gender differences on the M-blackboard learn cross tabulation was employed. This was done to see the perceived use of M-LMS. On the adopted of the blackboard the female learner tends to more agreed as it was appeared $(n=12)$ female learners and $(n=10)$ male learners were strongly agreed. The result indicate that the female learners ponder mobile integration is easy for LMS use for learning pursuits as compared to male learners. However, regarding disagreement $(n=8)$ female 
learners disagreed with its easiness. This assert that male learners tend to adopt technology more easily as compared to the female learners.

Another vital difference was compared in relation to its benefits for learning purposes. To this end $(n=6)$ male strongly agreed and $(n=12)$ agreed that it is useful for learning and $(n=6)$ disagreed with its usefulness. Female learners $(n=10)$ developed less interaction as compared to male leaners $(n=12)$ strongly agreed. In terms of its substitution with classroom teaching female $(n=9)$ strongly agreed with huge number of disagreeing numbers $(n=14)$. In contrast with this male learner $(n=8)$ agreed with this aspect. The finding of the analysis suggest that female learners consider the use of LMS on mobile phones more beneficial as compared to the male learners. Figure one and Table 5 demonstrates learners' preference of the usage of the software for remote learning.

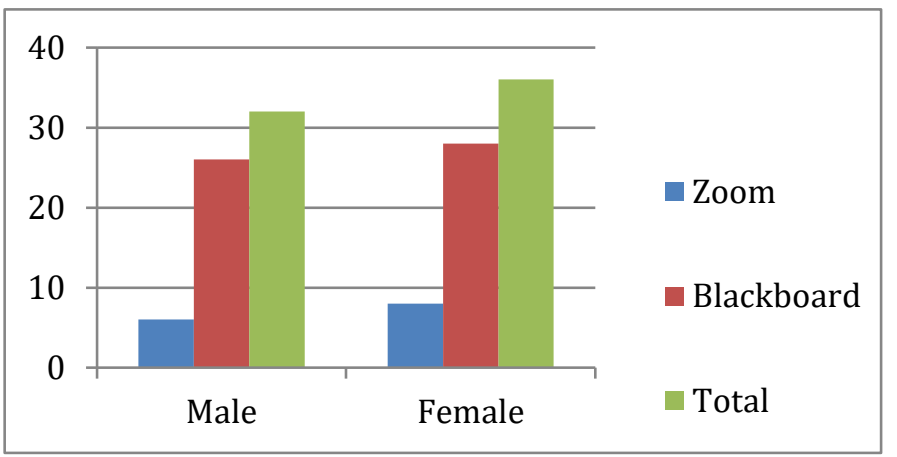

Fig. 2. Preference of Software Tool

Table 5. SOFTWARE * Gender Crosstabulation

\begin{tabular}{|c|l|c|c|c|}
\hline \multicolumn{2}{|c|}{} & \multicolumn{2}{|c|}{ Count } & \multirow{2}{*}{ Total } \\
\cline { 3 - 4 } \multicolumn{2}{|c|}{} & Male & Female & \\
\hline \multirow{2}{*}{ SOFTWARE } & Blackboard & 26 & 28 & 54 \\
\cline { 2 - 5 } & Zoom & 6 & 8 & 14 \\
\hline \multicolumn{2}{|c|}{ Total } & 32 & 36 & 68 \\
\hline
\end{tabular}

Learners were asked to indicate their preference on the tools they have used as eLearning platform during the Covid-19 outbreak. The results of the data analysis showed that a huge number of the learners both male and female consider blackboard for learning. As table 5 highlights that $(n=26$, male) and $(n=28$, female) participants adored the M-blackboard application for learning purposes. This numbers perceive that most of the learners liked to integrated Blackboard application as compared to the Zoom activities. This likeness possibly is the result of the various facilities that Blackboard presents for the enrichment of the learning environment. 


\section{Discussion}

The findings of the present inquiry were in some way indicate that Blackboard is effective in term of the delivering material to the learners. As up to 405 of the participants did not endorsed this idea. The results of the present inquiry are in the line Alkhaldi and Abualkishik (2019). The findings exhibited that students are confronting problems in attaining the desired advantages of the M-LMS. The learners in the present study also indicated some problems like internet speed creates problem. Though there appeared some frequency differences on certain elements of the learners' responses. However, the results of the present study are not in the line with the study by Han and Shin (2016) who studied the factors that affect the Blackboard learning. The results highlighted that the learners' self-efficacy in using mBlackboard has the perceived benefits in using the LMS. Moreover, the results indicated that learners had the encouraging remarks on the integration of Blackboard in the present study. The result of the present study also endorsed the finding of Papadakis et al. (2018) who also indicated learners' perceptions were affected by the certain factors of the mobile phone usage.

The result of present inquiry was endorsed by the studies by (Alshammari et al., 2016; Alshammari et al., 2018), who evaluated the acceptance of the LMS and selfefficacy. In addition to this they had asserted that technological and institutional aspects are also some of the challenges that learners and teachers face during the implementation of the Blackboard learning. This proclaim that the integration of Blackboard can be handy if it is used as blended learning environment. The results induce that the use of Blackboard application improves the self-learning which is important for the development of actual learning process.

The results are not in the line with the study conducted by Asiimwe (2015) on the ease of use of M-LMS. The results indicated that the learner did not like the idea of using Blackboard through mobile phones. Contrarily, the present inquiry has positive concerns on the usage of the M-blackboard learn. However, the data analysis assert that the finding endorse the findings of the Kaliisa and Picard (2017). The results showed that learners considered using blackboard useful through their mobile phones. Likewise, the finding are in partial consistent with Mtebe and Raisamo (2014). The results asserted that learners showed willingness to use M-LMS.

The use of smartphone optimizes the usage of LMS, and the findings presents that the learners were satisfied with its usage for learning. Thus, the instructors and designers of syllabus need to develop the content of the learning material to gain the advantage of the application usage with learning. Moreover, the outcomes of this inquiry, like other inquiries, underscore the significance of the presenting the contents as user friendly display, relevant, clear instruction and easy accessible (El Miedany, 2019; Heirdsfield et al., 2011). 


\section{Conclusion and Recommendation}

The focus of current inquiry was the explore the male and female learners on the use of mobile phones for Blackboard learn the analysis of the data indicate that the use of Blackboard application was considered effective. A vital proportion $(n=32 \%)$ strongly agreed that Blackboard facilitates learning and $(n=22 \%)$ agreed with this notion. Whereas only relatively small number of the learners $(n=15 \%)$ consider this ineffective. Likewise, the in the information and material delivery for the students also appeared to be on the average value of the statistics.

Learners also exhibited some challenges in the usage of Mblackboard learn. With the challenge aspect of the usage of the Mblackboard learners' responses were also somehow not satisfactory. Most of the learners $(n=34 \%)$, which is relatively higher proportion", indicated that internet speed creates problems, this is tailed by $(\mathrm{n}=15 \%)$. However, the similar type of the remarks was appeared as that internet is not a problem. In this regard $(n=33 \%)$ disagreed with this assertion. Another concern of the elearning is that it develops self-regulated learning. The analysis related to this aspect of the blackboard usage was somehow negative.

The results indicated that female learners, consider online learning a replacement to the conventional learning. The Cross tabulation showed the adoption of the blackboard was vital as compared to the male participants. The female learner tends to more agreed as it was appeared $(n=12)$ female learners and $(n=10)$ male learners were strongly agreed. Another vital difference was compared in relation to its benefits for learning purposes. To this end $(n=6)$ male strongly agreed and $(n=12)$ agreed that it is useful for learning and $(n=6)$ disagreed with its usefulness. Female learners developed less interaction as compared to male leaners. Finally, the results of the data analysis showed that a huge number of the learners both male and female consider the usage blackboard for learning. M-Blackboard is a valuable LMS that fosters the instructional improvement and constructivist prospects of the learning. Blackboard delivers cooperative and comprehensible, user-friendly situation learning and teaching process.

In the light of the above discussion and findings of the data, it can be asserted that backboard which is a form of learning can be beneficial if it is used with the traditional classroom teaching to get the potential benefits of the software. The study included only survey method in the present study. In order to underpin the effectiveness of MBlackboard learning an experimental study is essential to compare the possible effects of Blackboard learning.

\section{$7 \quad$ References}

[1]Al-Asmari, A. M., \& Khan, M. S. R. (2014). E-learning in Saudi Arabia: Past, present and future. Near and Middle Eastern Journal of Research in Education, 2014(1), 2. https://doi. org/10.5339/nmejre.2014.2

[2]Al-Emran, M., \& Salloum, S. A. (2017). Students' attitudes towards the use of mobile technologies in e-Evaluation. International Journal of Interactive Mobile Technologies (IJIM), 11(5), 195-202. https://doi.org/10.3991/ijim.v11i5.6879 
[3]Al Meajel, T. M., \& Sharadgah, T. A. (2018). Barriers to using the blackboard system in teaching and learning: Faculty perceptions. Technology, Knowledge and Learning, 23(2), 351-366. https://doi.org/10.1007/s10758-017-9323-2

[4]Alhabeeb, A., \& Rowley, J. (2017). Critical success factors for eLearning in Saudi Arabian universities. International Journal of Educational Management, 31(2), 131-147. https://doi. org/10.1108/ijem-01-2016-0006

[5]Alkhaldi, A., \& Abualkishik, A. (2019). The mobile blackboard system in higher education: Discovering benefits and challenges facing students. International Journal of Advanced and Applied Sciences, 9. https://doi.org/10.21833/ijaas.2019.06.002

[6]Alkhunzain, A. S. (2019). An Empirical Study on Smartphone Addiction of the University Students. International Journal of Interactive Mobile Technologies (IJIM), 13(12), 184195. https://doi.org/10.3991/ijim.v13i12.11120

[7]Alshammari, S. H., Ali, M. B., \& Rosli, M. S. (2016). The Influences of Technical Support, Self-Efficacy and Instructional Design on the Usage and Acceptance of LMS: A Comprehensive Review. Turkish Online Journal of Educational Technology-TOJET, 15(2), 116125.

[8]Alshammari, S. H., Bilal Ali, M., \& Rosli, M. S. (2018). LMS, CMS and LCMS: The confusion among them. Science International, 30(3), 455-459.

[9]Asiimwe, E. (2015). MLCMS actual use, perceived use, and experiences of use. International Journal of Education and Development using ICT, 11(1).

[10]Brand, J., Kinash, S., Mathew, T., \& Kordyban, R. (2011). iWant does not equal iWill: Correlates of mobile learning with iPads, e-textbooks, BlackBoard Mobile Learn and a blended learning experience. Proceedings ASCILITE 2011: 28th Annual Conference of the Australasian Society for Computers in Learning in Tertiary Education: Changing Demands, Changing Directions, pp. 168-178. https://doi.org/10.14742/ajet.832

[11]Bulman, G., \& Fairlie, R. W. (2016). Technology and education: Computers, software, and the internet Handbook of the Economics of Education (Vol. 5, pp. 239-280): Elsevier.

[12]Dorouka, P., Papadakis, S., \& Kalogiannakis, M. (2020). Tablets and apps for promoting robotics, mathematics, STEM education and literacy in early childhood education. International Journal of Mobile Learning and Organisation, 14(2), 255-274. https://doi.org/10.15 04/ijmlo.2020.10026334

[13]Dziuban, C., Graham, C. R., Moskal, P. D., Norberg, A., \& Sicilia, N. (2018). Blended learning: the new normal and emerging technologies. International Journal of Educational Technology in Higher Education, 15(1), 3. https://doi.org/10.1186/s41239-017-0087-5

[14]El Miedany, Y. (2019). e-Learning, Adaptive Learning and Mobile Learning Rheumatology Teaching (pp. 235-258): Springer. https://doi.org/10.1007/978-3-319-98213-7 13

[15]Glukhov, V., \& Vasetskaya, N. (2017). Improving the teaching quality with a smarteducation system. 2017 IEEE VI Forum Strategic Partnership of Universities and Enterprises of Hi-Tech Branches (Science. Education. Innovations) (SPUE), pp. 17-21. https:// doi.org/10.1109/ivforum.2017.8245958

[16]Han, I., \& Shin, W. S. (2016). The use of a mobile learning management system and academic achievement of online students. Computers \& Education, 102, 79-89. https://doi.org/ 10.1016/j.compedu.2016.07.003

[17]Heirdsfield, A., Walker, S., Tambyah, M., \& Beutel, D. (2011). Blackboard as an online learning environment: What do teacher education students and staff think? Australian Journal of Teacher Education (Online), 36(7), 1. https://doi.org/10.14221/ajte.2011v36n7.4

[18]Hsu, P.-S. (2016). Examining current beliefs, practices and barriers about technology integration: A case study. TechTrends, 60(1), 30-40. https://doi.org/10.1007/s11528-015-0014$\underline{3}$ 
[19]Ibrahim, L. K., Mohamed, A. G., Aldhafeeri, F. M., \& Alqdah, M. (2019). Faculty members' perceptions towards utilizing blackboard in teaching system at Hafr Al-Batin University, Saudi Arabia. Journal of Nursing Education and Practice, 9(5). https://doi.org/10.54 30/jnep.v9n5p64

[20]Jacob, S. M., \& Issac, B. (2008). Mobile technologies and its impact-an analysis in higher education context. International Journal of Interactive Mobile Technologies, 2(1).

[21]Kaliisa, R., \& Picard, M. (2017). A systematic review on mobile learning in higher education: The African perspective. Turkish Online Journal of Educational Technology-TOJET, 16(1), 1-18.

[22]Kalogiannakis, M., \& Papadakis, S. (2017). Combining mobile technologies in environmental education: a Greek case study. International Journal of Mobile Learning and Organisation, 11(2), 108-130. https://doi.org/10.1504/ijmlo.2017.10005249

[23]Kashghari, B., \& Asseel, D. (2014). Collaboration and interactivity in EFL learning via Blackboard Collaborate: A pilot study. Conference proceedings. ICT for language learning, p. 149.

[24]Khan, R., Radzuan, N., Alkhunaizan, A., Mustafa, G., \& Khan, I. (2019). The Efficacy of MALL Instruction in Business English Learning. International Journal of Interactive Mobile Technologies (IJIM), 13(8), 60-73. https://doi.org/10.3991/ijim.v13i08.9562

[25]Khan, R. M. I., Radzuan, N. R. M., Shahbaz, M., \& Ibrahim, A. H. (2018). EFL Instructors' Perceptions on the Integration and Implementation of MALL in EFL Classes. International Journal of Language Education and Applied Linguistics, 39-50.

[26]Khan, R. M. I., Radzuan, N. R. M., Shahbaz, M., Ibrahim, A. H., \& Mustafa, G. (2018). The role of vocabulary knowledge in speaking development of Saudi EFL learners. Arab World English Journal (AWEJ), 9(1), 406-418. https://doi.org/10.24093/awej/vol9no1.28

[27]Kitoo, S. M. (2020). Residential Faculty Members' Differential Use of Blackboard Tools: A Case Study.

[28]Little-Wiles, J., \& Naimi, L. L. (2011). Faculty Perceptions of and Experiences in using the Blackboard Learning Management System. Conflict Resolution \& Negotiation Journal(4).

[29]Mtebe, J. S., \& Raisamo, R. (2014). Investigating perceived barriers to the use of open educational resources in higher education in Tanzania. International Review of Research in Open and Distributed Learning, 15(2), 43-66. https://doi.org/10.19173/irrodl.v15i2.1803

[30]Muhammad, A., Shaikh, A., Naveed, Q. N., \& Qureshi, M. R. N. (2020). Factors Affecting Academic Integrity in E-Learning of Saudi Arabian Universities. An Investigation Using Delphi and AHP. IEEE Access, 8, 16259-16268. https://doi.org/10.1109/access.2020.29674 99

[31]Papadakis, S., Kalogiannakis, M., Sifaki, E., \& Vidakis, N. (2017). Access moodle using smart mobile phones. A case study in a Greek University Interactivity, Game Creation, Design, Learning, and Innovation (pp. 376-385): Springer. https://doi.org/10.1007/978-3319-76908-0_36

[32]Papadakis, S., Kalogiannakis, M., Sifaki, E., \& Vidakis, N. (2018). Evaluating Moodle use via Smart Mobile Phones. A case study in a Greek University. EAI Endorsed Transactions on Creative Technologies, 5(16). https://doi.org/10.4108/eai.10-4-2018.156382

[33]Papadakis, S., Kalogiannakis, M., Zaranis, N., \& Orfanakis, V. (2016). Using Scratch and App Inventor for teaching introductory programming in secondary education. A case study. International Journal of Technology Enhanced Learning, 8(3-4), 217-233. https://doi.org/ 10.1504/ijtel.2016.082317

[34]Papadakis, S., Vaiopoulou, J., Kalogiannakis, M., \& Stamovlasis, D. (2020). Developing and Exploring an Evaluation Tool for Educational Apps (ETEA) Targeting Kindergarten Children. Sustainability, 12(10), 4201. https://doi.org/10.3390/su12104201 
[35]Patten, M. L. (2016). Questionnaire research: A practical guide: Routledge.

[36]Quadri, N. N., Muhammed, A., Sanober, S., Qureshi, M. R. N., \& Shah, A. (2017). Barriers effecting successful implementation of e-learning in Saudi Arabian universities. International Journal of Emerging Technologies in Learning (iJET), 12(06), 94-107. https://doi. org/10.3991/ijet.v12i06.7003

[37]Ramírez-Montoya, M.-S., \& Hernández, D. d. C. R. (2016). Inverted learning environments with technology, innovation and flexibility: Student experiences and meanings. Journal of Information Technology Research (JITR), 9(1), 18-33. https://doi.org/10.4018/ji $\underline{\operatorname{tr} .2016010102}$

[38]Shahbaz, M., \& Khan, R. M. I. (2017). Use of mobile immersion in foreign language teaching to enhance target language vocabulary learning. MIER Journal of Educational Studies, Trends and Practices, 7(1).

[39]Zhang, X., Kuchinke, L., Woud, M. L., Velten, J., \& Margraf, J. (2017). Survey method matters: Online/offline questionnaires and face-to-face or telephone interviews differ. Computers in Human Behavior, 71, 172-180. https://doi.org/10.1016/j.chb.2017.02.006

\section{Authors}

Abdulmohsin AlKhunaizan is currently serving as an assistant professor at Majmaah University in the department of Information Systems and Computer Science. He is also serving as a Dean of PYP program of Majma'ah University. He holds a $\mathrm{PhD}$ in information system, Brunel University UK. His research interests include MCommerce, E-Learning and Mobile social network use. a.alkhunaizan@mu.edu.sa

Raja Muhammad Ishtiaq Khan is a Lecturer at Al-Majma'ah University, Saudi Arabia. He has a Cambridge CELTA certificate in teaching and has 10 years of experience in ESL and EFL. He holds PhD in Applied Linguistics and his research interests include Applied Linguistics, MALL, L2 Vocabulary learning and Teaching, Second Language Acquisition and EFL teaching.

Article submitted 2020-07-13. Resubmitted 2020-09-05. Final acceptance 2020-09-06. Final version published as submitted by the authors. 